(2) Open Access Full Text Article

\title{
Dexmedetomidine reduces the neuronal
}

\section{apoptosis related to cardiopulmonary bypass by inhibiting activation of the JAK2-STAT3 pathway}

This article was published in the following Dove Press journal:

Drug Design, Development and Therapy

26 September 2017

Number of times this article has been viewed

\author{
Yanhua Chen ${ }^{1, *}$ \\ Xu Zhang ${ }^{2, *}$ \\ Bingdong Zhang' \\ Guodong $\mathrm{He}^{2}$ \\ Lifang Zhou ${ }^{2}$ \\ Yubo $\mathrm{Xie}^{2}$ \\ 'Department of Anesthesiology, \\ Cardiovascular Institute, ${ }^{2}$ Department \\ of Anesthesiology, the First Affiliated \\ Hospital of Guangxi Medical \\ University, Nanning, China \\ *These authors contributed equally \\ to this work
}

Correspondence: Yubo Xie

Department of Anesthesiology, the First Affiliated Hospital of Guangxi Medical

University, 6 Shuangyong Road, Nanning,

Guangxi 53002I, China

Tel +86 77l 5356250

Email xybdoctor@163.com

\begin{abstract}
Cardiopulmonary bypass (CPB) constitutes one of the primary methodologies pertaining to cardiac surgery. However, this form of surgery can cause damage to the body. Many studies have reported that dexmedetomidine confers cerebral protection. In this study, we aimed to investigate the effect and mechanism of dexmedetomidine on neuronal apoptosis caused by CPB. Here, rats were treated with different doses of dexmedetomidine by intravenous infusion 2 hours after CPB. We observed that dexmedetomidine treatment to rats reduces the S100ß, NSE levels in plasma, and neuronal apoptosis following CPB in a dose-dependent manner. Furthermore, we observed that the beneficial effect of dexmedetomidine treatment following CPB was associated with a reduction in IL6, an inflammatory cytokine in plasma and cortex. Our results suggest that dexmedetomidine provides neuroprotective effects by inhibiting inflammation and reducing neuronal apoptosis. There was a correlation between the protective effect on the brain and the dose of dexmedetomidine. In addition, dexmedetomidine administration inhibits phosphorylation of JAK2 and STAT3 proteins in the hippocampus of rats 2 hours after CPB. Therefore, we speculate that the JAK2-STAT3 pathway plays an important role in the neuroprotective effects of dexmedetomidine following brain injury induced by CPB.
\end{abstract}

Keywords: apoptosis, cardiopulmonary bypass, dexmedetomidine, neuroprotective effect, JAK2, STAT3

\section{Introduction}

Cardiopulmonary bypass (CPB) is the predominant technique associated with cardiovascular surgery, and this form of surgery is known to improve the curative rate pertaining to numerous cardiac diseases. However, CPB can induce an abnormal physiological status, which can cause damage to the body. ${ }^{1}$ Following blood contact with the inner surfaces of the CPB apparatus, the complement system is activated and in turn stimulates release of proinflammatory cytokines, thereby influencing inflammatory response. ${ }^{2}$ Consequently, nervous system complications have become a concern after CPB. ${ }^{3}$ Many studies have been performed to elucidate the mechanisms that mediate the occurrence of brain injury following $\mathrm{CPB},{ }^{4,5}$ and an increasing number of treatments are now used to prevent brain injury caused by CPB. ${ }^{6}$ Several studies have shown that CPB-mediated brain injury is associated with embolism, hypoperfusion, arrhythmias, rapid rewarming, and inflammation. ${ }^{3,4,7}$ Moreover, a substantial amount of research has been conducted into brain injury associated with CPB in relation to different cell factors and signal pathways. ${ }^{5,8}$ 
Dexmedetomidine is an $\alpha_{2}$-adrenergic receptor agonist, and is known to exhibit sedative, analgesic, and anti-sympathetic nerve activities. It has been widely used in clinical anesthesia and sedation in intensive care units. Dexmedetomidine can significantly reduce cerebral injury induced by transient global cerebral ischemia-reperfusion in diabetic rats, mainly through altering the oxidative stress markers and inflammatory cytokines. ${ }^{9}$ Recent studies have shown that dexmedetomidine exhibits renoprotective effects following renal ischemia-reperfusion injury by inhibiting JAK-STAT signaling pathway. Investigators have also found similar renoprotective effects upon AG490 treatment, an inhibitor of JAK2. ${ }^{10,11}$

The JAK-STAT signaling pathway is not only involved in renal protection but also involved in brain protection. ${ }^{12}$ AG490 reduces brain injury and inflammatory responses in rats following heatstroke by inhibiting the activation of the JAK2-STAT3 pathway. ${ }^{13}$ The STAT3 signaling pathway is activated following traumatic brain injury, and may be involved in the recovery of neurological function. ${ }^{14,15}$ We investigated the effect of different doses of dexmedetomidine on cerebral injury related to CPB. Furthermore, the study aimed to characterize whether JAK2-STAT3 signaling was involved in dexmedetomidine-induced neuroprotection following CPB.

\section{Materials and methods}

\section{Animals and grouping}

A total of 96 adult male Sprague Dawley rats weighing 300-350 g were provided by the Guangxi Medical University Laboratory Animal Center. Animal experiments and protocols were approved by the medical ethics committee of the First Affiliated Hospital of Guangxi Medical University (2016[KY-E-002]).

Rats were randomly divided into six experimental groups of 16 rats in each group. In group 1, rats did not undergo surgical operation for CPB, and hence served as sham controls (group Sham). In group 2, all 16 rats underwent surgery to develop CPB as a model system. Rats in group 2 did not receive any treatment, and hence served as CPB control (group CPB). Rats in groups 3 and 4 received $1 \mu \mathrm{g} / \mathrm{mL}$ dexmedetomidine (Jiangsu Hengrui Medicine, Lianyungang, China), which was diluted with $0.9 \%$ saline. In addition, rats in groups 3 and 4 received loading doses of dexmedetomidine $2.5 \mu \mathrm{g} / \mathrm{kg}$ (low dose [group L]) and $5 \mu \mathrm{g} / \mathrm{kg}$ (high dose [group H]) intravenously using a microinfusion pump 15 minutes before CPB. Then, maintenance doses of dexmedetomidine $-2.5 \mu \mathrm{g} / \mathrm{kg} / \mathrm{h}$ (group L) or $5 \mu \mathrm{g} / \mathrm{kg} / \mathrm{h}$ (group H) - were administered intravenously during the $\mathrm{CPB}$ procedure after the loading the dose. In group 5, rats received AG490 (Selleck Chemicals, Dallas, TX, USA), a JAK2 inhibitor, at a dose of $10 \mathrm{mg} / \mathrm{kg}$ intraperitoneally, and served as the AG490 group (10 mg AG490 diluted with $0.6796 \mathrm{~mL}$ dimethyl sulfoxide [DMSO] and then diluted with physiological saline). ${ }^{11}$ In group 6, rats received DMSO at a dose of $0.6796 \mathrm{~mL} / \mathrm{kg}$, intraperitoneally (0.6796 mL DMSO in physiological saline as vehicle dose), and served as the DMSO group.

\section{CPB-model preparation}

Rats were anesthetized with pentobarbital sodium $(65 \mathrm{mg} / \mathrm{kg}$ intraperitoneally) and mechanically ventilated to maintain end-tidal carbon dioxide between 35 and $45 \mathrm{mmHg}$. The protocol followed for the development of this CPB model has been described previously. ${ }^{16}$ To sustain mean arterial pressure of 70-85 mmHg and hematocrit of approximately $20 \%-25 \%$, each rat was covered with a heat lamp to maintain the body central temperature at $36.5^{\circ} \mathrm{C} \pm 1^{\circ} \mathrm{C}$ throughout the experiment. The CPB procedure continued for 2 hours.

\section{Specimen collection and processing}

Venous blood samples $(n=8)$ were collected prior to CPB $\left(t_{0}\right), 1$ hour after CPB $\left(t_{1}\right)$, and 2 hours after CPB $\left(t_{2}\right)$. Blood samples were centrifuged at $1,000 \mathrm{~g}$ for 15 minutes. Plasma supernatants were harvested and stored at $-20^{\circ} \mathrm{C}$ for enzymelinked immunosorbent assay (ELISA).

Rats were killed and fresh brain-tissue samples collected 2 hours after CPB $(n=8)$. Hippocampal tissue samples were harvested to determine JAK2, pJAK2, STAT3, pSTAT3, and cleaved caspase- 3 protein levels. Tissue samples were frozen and stored at $-80^{\circ} \mathrm{C}$ prior to Western blot analysis. Parietal cortices were weighed according to the proportion of $100 \mathrm{mg}$ hippocampal tissue homogenized in $1 \mathrm{~mL}$ PBS, and stored overnight at $-20^{\circ} \mathrm{C}$. After two freeze-thaw cycles had been performed to break the cell membranes, homogenates were centrifuged for 5 minutes at $5,000 \mathrm{~g}, 2^{\circ} \mathrm{C}-8^{\circ} \mathrm{C}$. The supernatant was collected and stored at $-20^{\circ} \mathrm{C}$ for analysis of IL6 and IL10 using ELISA. The remaining fresh brain tissue was used for determination of brain water content.

Other rats ( $n=7$ for groups $\mathrm{CPB}$ and DMSO, $\mathrm{n}=8$ for other groups) were subjected to cerebral perfusion for TUNEL assay and immunohistochemistry. Transcardial perfusions were performed after blocking the abdominal aorta (100 mL 0.9\% saline, followed by $200 \mathrm{~mL}$ refrigerated $4 \%$ paraformaldehyde solution). Brains were removed, cut open along the coronal incision at $4 \mathrm{~mm}$ after the optic chiasma, and $2 \mathrm{~mm}$-thick hippocampal tissue was excised and stored 
in refrigerated paraformaldehyde ( $<24$ hours). Specimens were then dehydrated by being passed through graded series of ethanol, cleared in xylene, and embedded in paraffin wax. The paraffin-embedded hippocampal tissues were cut into $4 \mu \mathrm{m}$ sections.

\section{Enzyme-linked immunosorbent assay}

All biomarkers were analyzed using commercially available ELISA kits. Plasma samples were analyzed for IL6 (Cusabio Biotech, Wuhan, China), IL10 (Thermo Fisher Scientific, Waltham, MA, USA), S100ß (Cusabio Biotech), and NSE (Cusabio Biotech). Cortex samples were analyzed using ELISA according to the ELISA-kit manufacturer's instructions for IL6 and IL10.

\section{Western blot analysis for JAK2, pJAK2, STAT3, PSTAT3, and cleaved caspase 3}

For Western blot analysis, proteins from different groups were extracted and protein concentration quantified. Then, samples were used for routine Western blot analysis; the detailed protocol has been described previously. ${ }^{17}$ Antibodies were replaced by the primary antibodies JAK2 (1:1,000, AB_2128522; Cell Signaling Technology, Danvers, MA, USA), phospho-JAK2 (phospho-Y1007 + Y1008, 1:1,000, AB_775808; Abcam, Cambridge, UK), STAT3 (1:1,000, AB_331269; Cell Signaling Technology), phospho-STAT3 (Tyr705, 1:1,000, AB_1658549; Abcam), cleaved caspase 3 (1:1,000, AB_2070042; Cell Signaling Technology), and $\beta$-actin (1:3,000; Bioworld Technology, Minneapolis, MN, USA). The secondary antibody was horseradish peroxidase conjugated to goat antirabbit/mouse IgG (1:10,000; Cell Signaling Technology). The membranes were developed using an Odyssey two-color infrared scanner (LI-Cor Biosciences, Lincoln, NE, USA).

\section{Brain water content}

Fresh brain tissue was weighed promptly after removal of the parietal cortex and hippocampus. Brain water content was measured using the standard wet/dry weight method. ${ }^{18}$

\section{Detection of apoptosis of hippocampal neurons and cortex by TUNEL assay}

Apoptosis of hippocampal neurons in the CA1 region and the parietal cortex adjacent to the CA1 region was monitored using a TUNEL-assay kit according to the manufacturer's instructions and finally observed under microscopy. All TUNEL-positive cells were counted, and numbers of apoptotic cells were calculated for each area. ${ }^{9}$

\section{Immunohistochemistry}

The immunohistochemistry protocol followed in this study was as previously described. ${ }^{19,20}$ After being blocked in $3 \% \mathrm{H}_{2} \mathrm{O}_{2}$ and $3 \%$ normal goat serum, tissue sections were incubated with anti-pJAK2 antibody (dilution 1:200) or anti-pSTAT3 antibody (dilution 1:100) rabbit monoclonal antibodies in PBS overnight.

\section{Statistical analysis}

Data are presented as means \pm SEM. All statistical analyses were performed using SPSS 16.0 (SPSS Inc, Chicago, IL, USA). Multiple comparisons were performed with one-way analysis of variance, followed by Tukey's post hoc test. $P$-values $<0.05$ were considered significant.

\section{Results}

A total of 96 rats were used. Two rats (one in group CPB and one in group DMSO) were excluded, due to survival failure. The remaining 94 rats were used for analysis of various parameters. Venous blood samples and cortex samples were collected for ELISA $(n=8)$. Hippocampal tissue samples were harvested for Western blot analysis $(n=8)$. The remaining fresh brain-tissue samples were used for determination of brain water content $(n=8)$. Other rats ( $n=7$ for group CPB and group DMSO, $n=8$ for other groups) were subjected to cerebral perfusion for TUNEL assay and immunohistochemistry.

\section{Dexmedetomidine reduced brain water content in rats following CPB}

The brain water content in group CPB was significantly increased compared with group Sham $(P<0.05)$. The brain water content in group AG490, group L, and group H was significantly decreased compared with group CPB $(P<0.05)$. However, there was no significant difference between group $\mathrm{L}$ and group $\mathrm{H}$ in brain water content $(P>0.05$, Figure 1). Not surprisingly, DMSO-administered rats did not shown significant decreases in brain water level, which indicates the vehicle dose of DMSO used in this study did not play any pharmacological role.

\section{Dexmedetomidine decreased SIOO $\beta$ and NSE plasma levels in CPB rat model}

S100 $\beta$ and NSE are major biomarkers of brain injury and mainly used in brain trauma, cerebral stroke and hypoxic ischemia encephalopathy. We measured levels of these markers by ELISA. Remarkably, ELISA indicated levels of $\mathrm{S} 100 \beta$ and NSE in plasma were significantly increased in 


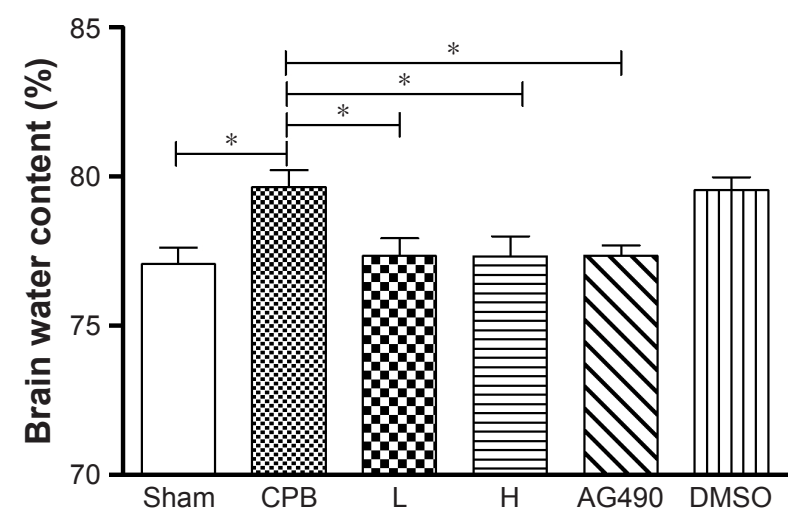

Figure I Brain water content in rats after 2 hours of CPB.

Notes: AG490 administered at $10 \mathrm{mg} / \mathrm{kg}$ intraperitoneally, DMSO at $0.6796 \mathrm{~mL} / \mathrm{kg}$ intraperitoneally. $* P<0.05$.

Abbreviations: CPB, cardiopulmonary bypass; L, low dose (dexmedetomidine $2.5 \mu \mathrm{g} / \mathrm{kg} / \mathrm{h}$ ); H, high dose (dexmedetomidine $5 \mu \mathrm{g} / \mathrm{kg} / \mathrm{h}$ ); DMSO, dimethyl sulfoxide.

group CPB compared with group Sham at $t_{1}$ and $t_{2}$, respectively $(P<0.05)$. Compared with group $\mathrm{CPB}$, a decrease in S100 $\beta$ and NSE plasma levels was observed in group $L$ at $t_{2}(P<0.05)$. Compared with group CPB, a decrease in $\mathrm{S} 100 \beta$ and NSE plasma levels was also observed in group AG490 and group $\mathrm{H}$ at the $t_{1}$ and $t_{2}$ time points $(P<0.05)$, whereas group L showed a significant effect at $t_{2}$. S100 $\beta$ and NSE plasma levels in group $\mathrm{H}$ were significantly decreased compared with group $\mathrm{L}$ at $t_{1}$ and $t_{2}(P<0.05$, Figure 2$)$.

\section{Dexmedetomidine reduced apoptosis of hippocampus and cortex}

To evaluate apoptosis of hippocampal neurons and cortex region induced by CPB, a TUNEL assay was performed.
Interestingly, we observed marked TUNEL-positive cells indicated apoptosis of hippocampal neurons in the CA1 region of CPB-group rats, which was significantly comparable to that of group Sham $(P<0.05)$. Apoptosis of hippocampal neurons in the CA1 region in group AG490, group L, and group $\mathrm{H}$ was significantly decreased compared with group CPB $(P<0.05)$. Apoptosis of hippocampal neurons in the $\mathrm{CA} 1$ region in group $\mathrm{H}$ was significantly decreased compared with group L $(P<0.05$, Figure 3$)$.

As expected, apoptosis of cortex in group CPB was significantly increased compared with group Sham $(P<0.05)$. Apoptosis of cortex in group AG490, group L, and group H was significantly decreased compared with group $\mathrm{CPB}$ $(P<0.05)$. Apoptosis of cortex in group $\mathrm{H}$ was significantly decreased compared with group L $(P<0.05$, Figure 4$)$.

\section{Dexmedetomidine reduced IL6 levels in plasma and cortex}

Levels of IL6 and IL10 in plasma were significantly increased in group CPB compared with group Sham at $t_{1}$ and $t_{2}(P<0.05)$. Compared with group CPB, decreased IL6 was observed in group AG490, group L, and group H at $t_{2}(P<0.05)$. Compared with CPB group, no significant difference in IL10 was observed in group DMSO, group AG490, group $\mathrm{L}$, or group $\mathrm{H}$ at $t_{1}$ or $t_{2}(P>0.05)$. There was no significant difference between group $\mathrm{L}$ and group $\mathrm{H}$ in plasma levels of IL6 or IL10 ( $P>0.05$, Figure 5).

Levels of IL6 and IL10 in cortex in group CPB were significantly increased compared with group Sham $(P<0.05)$.
A

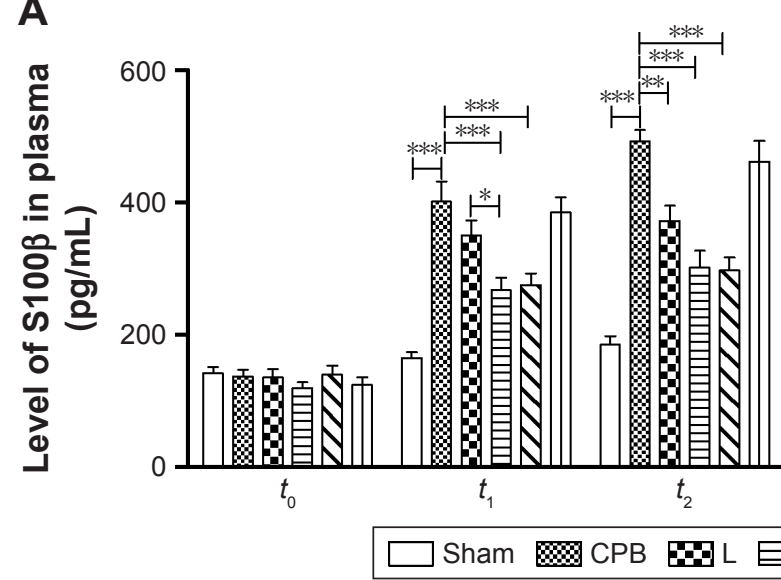

B

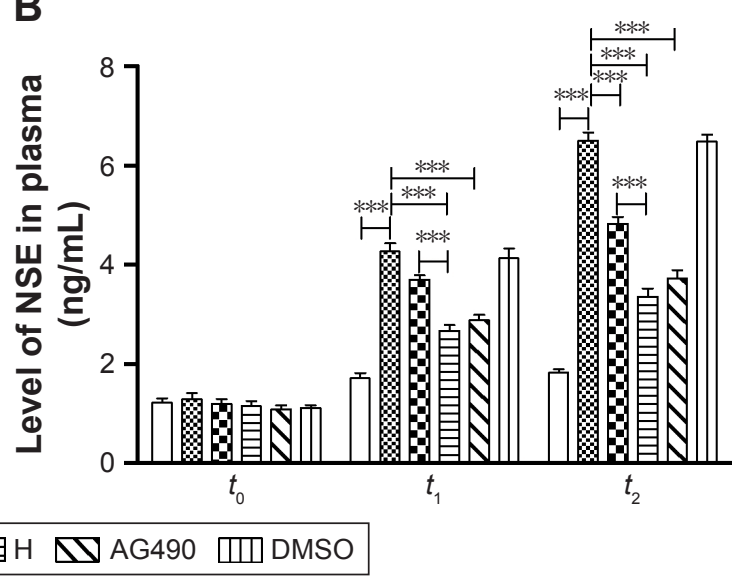

Figure 2 Levels of SIOO $\beta$ and NSE in plasma.

Notes: (A) SIO0 $\beta$ level; (B) NSE level. SIO0 $\beta$ and NSE levels in plasma were significantly increased in the CPB group compared with the Sham group at $t_{1}$ and $t_{2}$, respectively $(P<0.05)$. Compared with the CPB group, decreases in SI00 $\beta$ and NSE plasma levels were observed in group $L$ at $t_{2}(P<0.05)$. Compared with the CPB group, decreases in SI00 $\beta$ and NSE plasma levels were also observed in the AG490 group and the $\mathrm{H}$ group at $t_{1}$ and $t_{2}(P<0.05)$. SI00 $\beta$ and NSE plasma levels in the $\mathrm{H}$ group were significantly decreased compared with the $L$ group at $t_{1}$ and $t_{2}(P<0.05)$. AG490 administered at $10 \mathrm{mg} / \mathrm{kg}$ intraperitoneally, DMSO at $0.6796 \mathrm{~mL} / \mathrm{kg}$ intraperitoneally. $* P<0.05 ; * * P<0.0 \mathrm{I} ; * * * P<0.00 \mathrm{I}$. Abbreviations: CPB, cardiopulmonary bypass; L, low dose (dexmedetomidine $2.5 \mu \mathrm{g} / \mathrm{kg} / \mathrm{h}$ ); $\mathrm{H}$, high dose (dexmedetomidine $5 \mu \mathrm{g} / \mathrm{kg} / \mathrm{h}$ ); DMSO, dimethyl sulfoxide. 


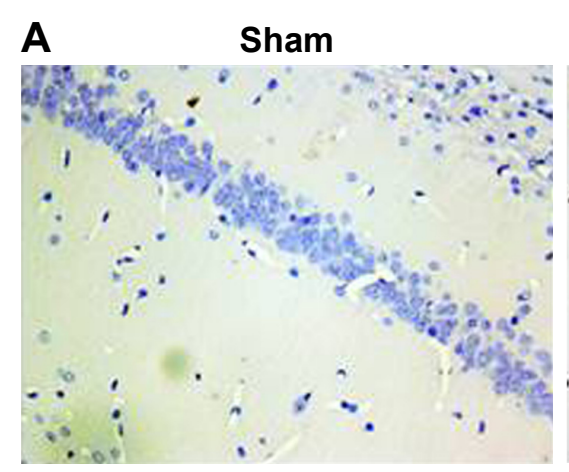

H
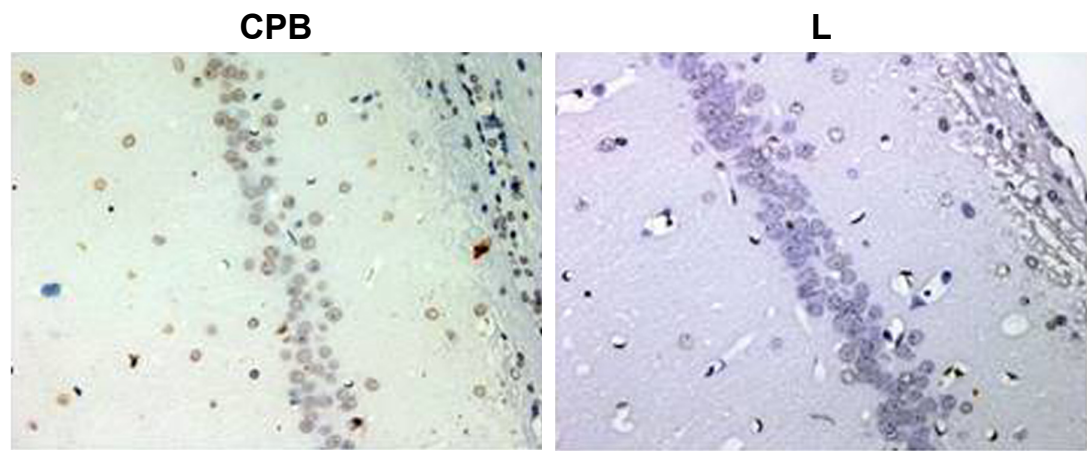

AG490

DMSO
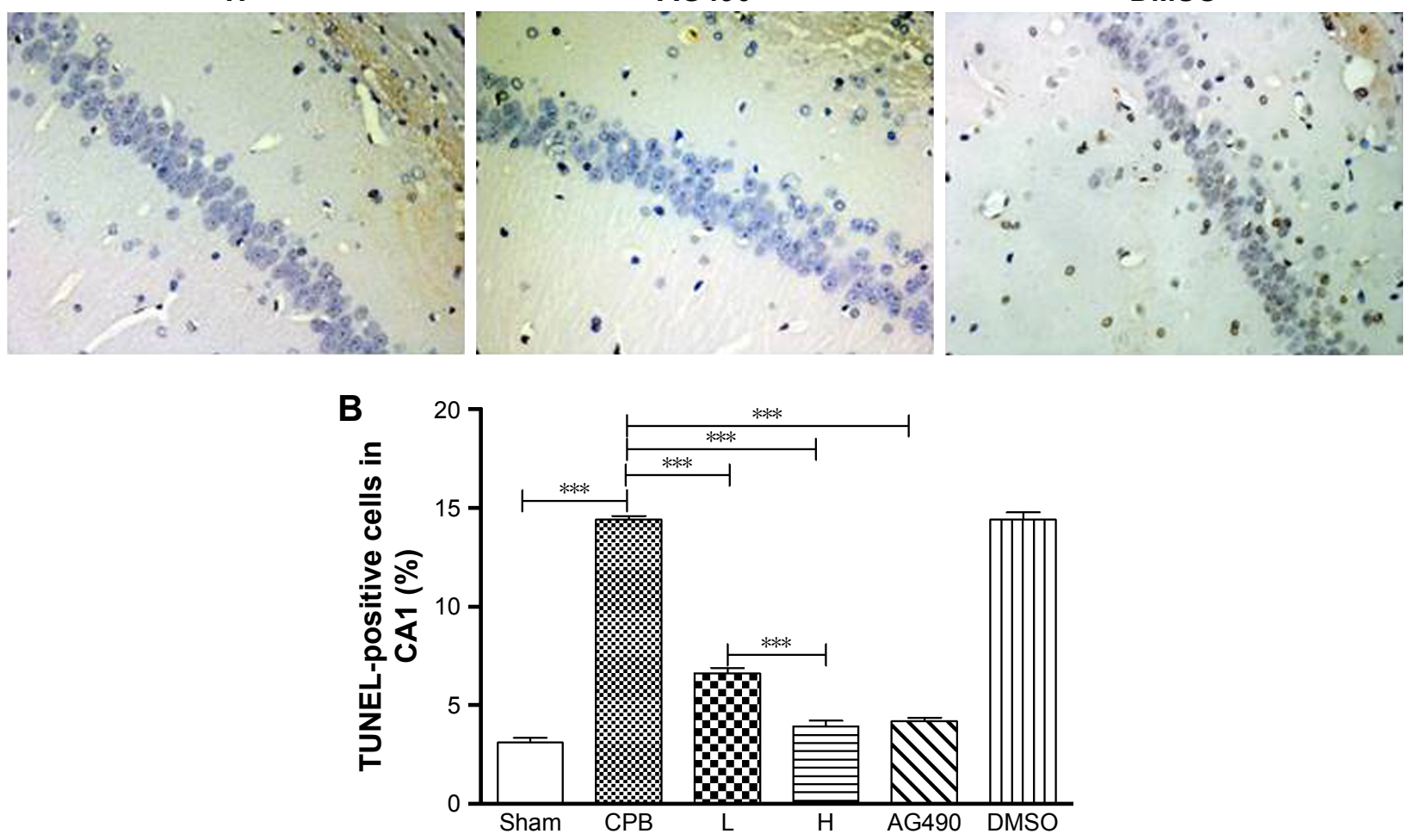

Figure 3 TUNEL-positive cells in the hippocampal CAI region.

Notes: (A) Representative TUNEL-assay images of hippocampal CAI region (400X); (B) TUNEL-positive cells in CAI region. AG490 administered at I0 mg/kg intraperitoneally, DMSO at $0.6796 \mathrm{~mL} / \mathrm{kg}$ intraperitoneally. $* * * P<0.001$.

Abbreviations: DMSO, dimethyl sulfoxide; CPB, cardiopulmonary bypass; L, low dose (dexmedetomidine $2.5 \mu \mathrm{g} / \mathrm{kg} / \mathrm{h}$ ); H, high dose (dexmedetomidine $5 \mu \mathrm{g} / \mathrm{kg} / \mathrm{h}$ ).

Compared with group $\mathrm{CPB}$, a decrease in cortex IL6 was observed in group AG490, group L, and group $\mathrm{H}(P<0.05)$. Compared with the CPB group, no significant difference in cortex IL10 was observed in group AG490, group L, or group $\mathrm{H}(P>0.05)$. There was no significant difference between group L and group H in IL6 or IL10 cortex levels $(P>0.05$, Figure 6).

\section{Dexmedetomidine decreased expression of cleaved caspase- 3 protein in hippocampus}

To confirm TUNEL positivity for apoptotic cell death in hippocampal neurons and the cortex region, we assessed cleaved caspase-3 protein expression, which is the most important protein in intrinsic apoptotic signals. Western blot was performed, and showed significantly increased expression of cleaved caspase 3 in group CPB rat hippocampi when compared with group Sham $(P<0.05)$. However, dramatically decreased expression of cleaved caspase 3 was seen in group AG490, group L, and group $\mathrm{H}$ compared with group CPB $(P<0.05)$. These data revealed that dexmedetomidine can potentially protect cells from CPB-mediated apoptotic cell death. However, there was no significant difference between group $\mathrm{L}$ and group $\mathrm{H}$ in cleaved caspase-3 protein levels $(P>0.05$, Figure 7$)$, which indicated a more pronounced effect of dexmedetomidine. 


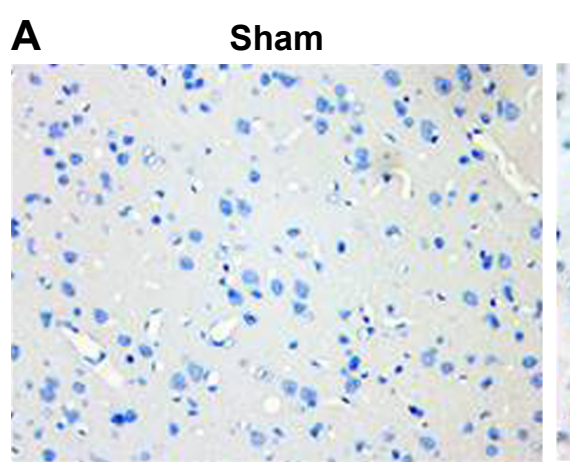

H

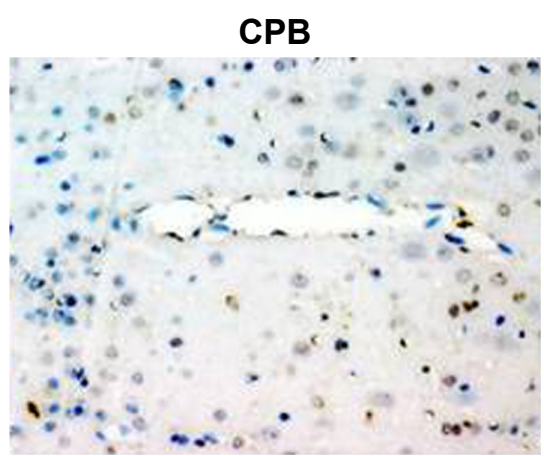

AG490

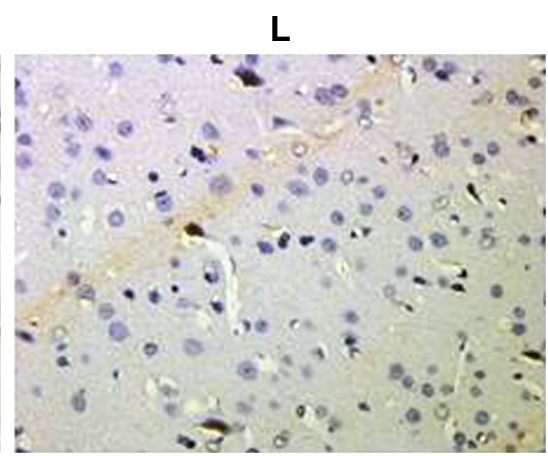

DMSO
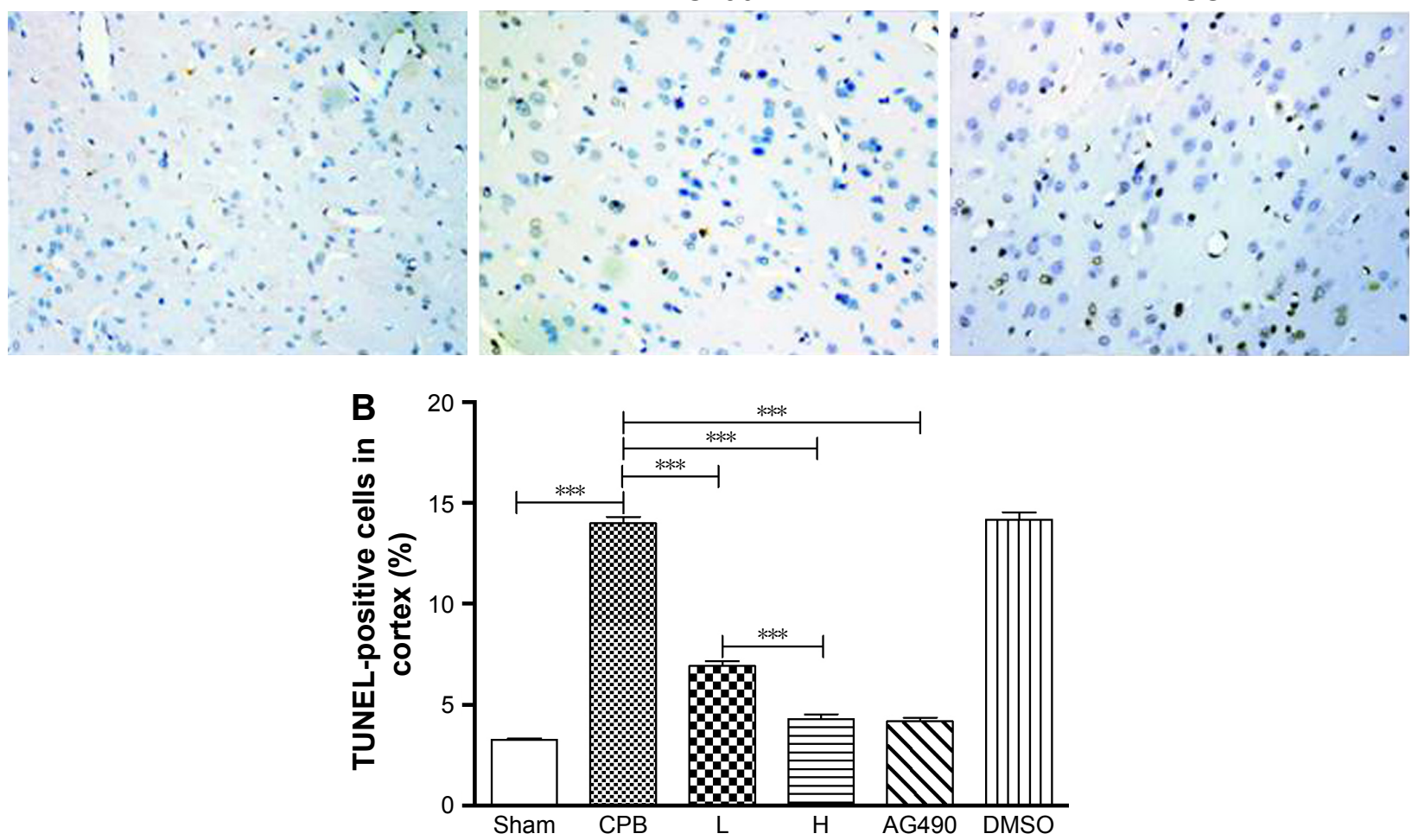

Figure 4 TUNEL-positive cells in cortex.

Notes: (A) Representative TUNEL-assay cortex images (400×); (B) TUNEL-positive cells in cortex. AG490 administered at $10 \mathrm{mg} / \mathrm{kg}$ intraperitoneally, DMSO at 0.6796 mL/kg intraperitoneally. $* * * P<0.001$

Abbreviations: DMSO, dimethyl sulfoxide; CPB, cardiopulmonary bypass; L, low dose (dexmedetomidine $2.5 \mu \mathrm{g} / \mathrm{kg} / \mathrm{h})$; H, high dose (dexmedetomidine $5 \mu \mathrm{g} / \mathrm{kg} / \mathrm{h})$.

\section{Dexmedetomidine decreased expression of PJAK2 and PSTAT3 proteins in hippocampus}

Next, we investigated the underlying mechanisms of the neuroprotective effect of dexmedetomidine. Western blot analysis and immunohistochemistry data revealed that expression of $\mathrm{pJAK} 2$ and $\mathrm{pSTAT} 3$ proteins in group $\mathrm{CPB}$ was significantly increased compared with group Sham $(P<0.05)$. Furthermore, pJAK2 and pSTAT3 expression in group AG490, group L, and group $\mathrm{H}$ was significantly decreased compared with group CPB $(P<0.05)$, whereas there were no significant changes in total JAK2 or STAT3 proteins. However, there was no significant difference between group L and group $\mathrm{H}$ in the expression of $\mathrm{pJAK} 2$ or $\mathrm{pSTAT} 3$ protein ( $P>0.05$, Figures $8-11)$. This significant inhibition of JAK2 and STAT3 phosphorylation by dexmedetomidine treatment shows promising anti-inflammatory effects.

\section{AG490 attenuated neuroapoptosis related to CPB and decreased PJAK2 and PSTAT3}

To elucidate the role of JAK2-STAT3 signaling in dexmedetomidine-attenuated CPB-related neuroapoptosis further, we administered a JAK2 inhibitor (AG490), which resulted in a significant decrease in the apoptosis of hippocampus and cortex (Figures 3 and 4). pJAK2 and pSTAT3 protein 
A

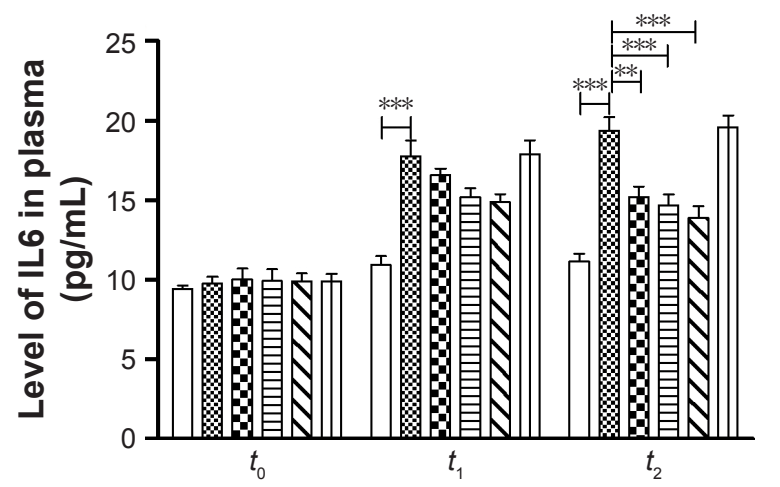

B

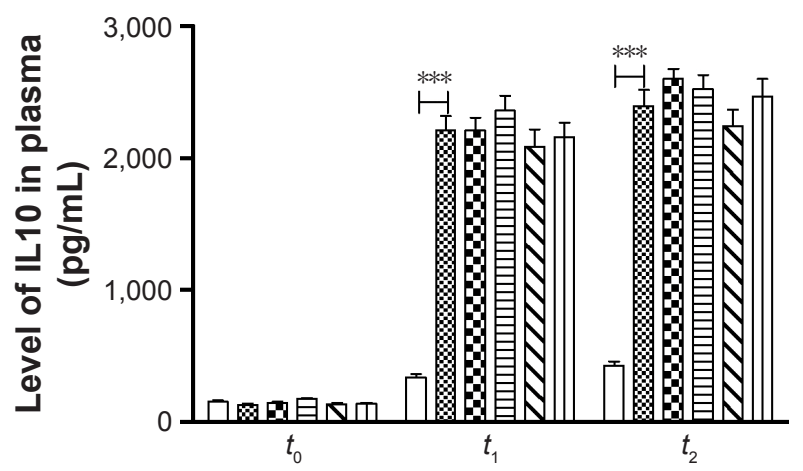

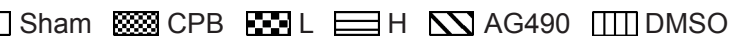

Figure 5 Levels of IL6 and ILI 0 in plasma.

Notes: (A) IL6 levels; (B) ILI0 levels. IL6 and ILI0 levels in plasma were significantly increased in group CPB compared with group Sham at $t_{1}$ and $t_{2}(P<0.05)$. Compared with group CPB, a decrease in IL6 plasma level was observed in group $A G 490$, group $\mathrm{L}$, and group $\mathrm{H}$ at $t_{2}(P<0.05)$. Compared with the $C P B$ group, no significant difference in ILIO level was observed in group DMSO, group $A G 490$, group $L$, or group $\mathrm{H}$ at $t_{1}$ or $t_{2}(P>0.05)$. There was no significant difference between group $\mathrm{L}$ and group $\mathrm{H}$ in plasma levels of IL6 or ILIO (P>0.05). AG490 administered at $10 \mathrm{mg} / \mathrm{kg}$ intraperitoneally, DMSO at $0.6796 \mathrm{~mL} / \mathrm{kg}$ intraperitoneally. $* * P<0.0 \mathrm{I} ; * * * P<0.00 \mathrm{I}$.

Abbreviations: CPB, cardiopulmonary bypass; L, low dose (dexmedetomidine $2.5 \mu \mathrm{g} / \mathrm{kg} / \mathrm{h}$ ); $\mathrm{H}$, high dose (dexmedetomidine $5 \mu \mathrm{g} / \mathrm{kg} / \mathrm{h}$ ); DMSO, dimethyl sulfoxide.

expression decreased significantly in group AG490 compared with group CPB on both Western blot analysis and immunohistochemistry positivity (Figures 8-11). The effect of dexmedetomidine in CPB rats was similar to that of AG490. This observation suggested that the JAK2-STAT3 signaling pathway played a significant role in dexmedetomidinemediated neuroprotection.

\section{Dexmedetomidine attenuated brain injury related to CPB in a dose- dependent manner}

To determine the protective effect of different doses of dexmedetomidine on brain injury in rats undergoing $\mathrm{CPB}$, a maintenance dose of $2.5 \mu \mathrm{g} / \mathrm{kg} / \mathrm{h}$ was administered in group L and a maintenance dose of $5 \mu \mathrm{g} / \mathrm{kg} / \mathrm{h}$ administered in group $\mathrm{H}$.
Dexmedetomidine administration to $\mathrm{CPB}$ rats resulted in significant decreases in brain-injury biomarkers, such as S100 $\beta$ and NSE, in plasma levels at $t_{1}$ and $t_{2}$, and S100 $\beta$ and NSE plasma levels in group $\mathrm{H}$ were more pronounced when compared with group L at $t_{1}$ and $t_{2}$ (Figure 2). Meanwhile, dexmedetomidine significantly reduced apoptosis of hippocampal neurons and the cortex region, and apoptosis of hippocampus and cortex in group $\mathrm{H}$ was significantly decreased compared with group L (Figures 3 and 4). These results suggest that dexmedetomidine attenuated brain injury related to $\mathrm{CPB}$ in a dose-dependent manner.

\section{Discussion}

In this study, we investigated the neuroprotective effects of dexmedetomidine using a rat model of CPB. We observed
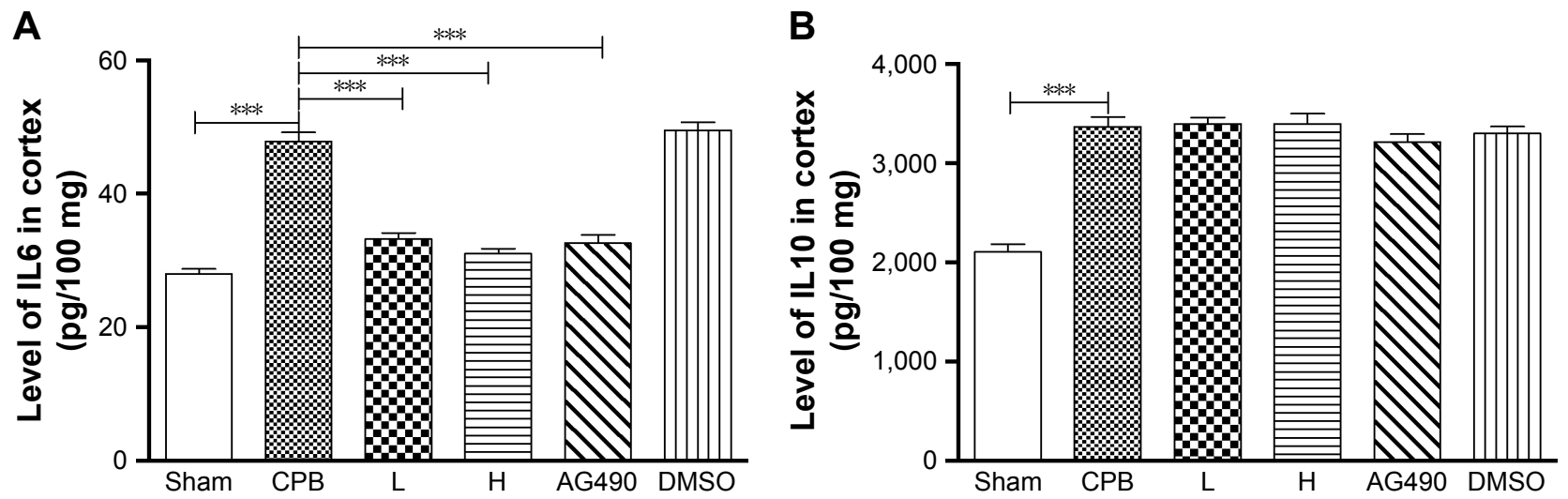

Figure 6 Levels of IL6 and ILI 0 in cortex.

Notes: (A) IL6 levels; (B) ILI0 levels. AG490 administered at $10 \mathrm{mg} / \mathrm{kg}$ intraperitoneally, DMSO at $0.6796 \mathrm{~mL} / \mathrm{kg}$ intraperitoneally. $* * * P<0.00$ I.

Abbreviations: DMSO, dimethyl sulfoxide; CPB, cardiopulmonary bypass; L, low dose (dexmedetomidine $2.5 \mu \mathrm{g} / \mathrm{kg} / \mathrm{h}$ ); $\mathrm{H}$, high dose (dexmedetomidine $5 \mu \mathrm{g} / \mathrm{kg} / \mathrm{h}$ ). 
A

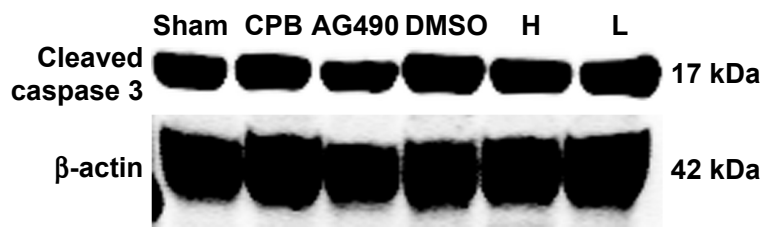

B

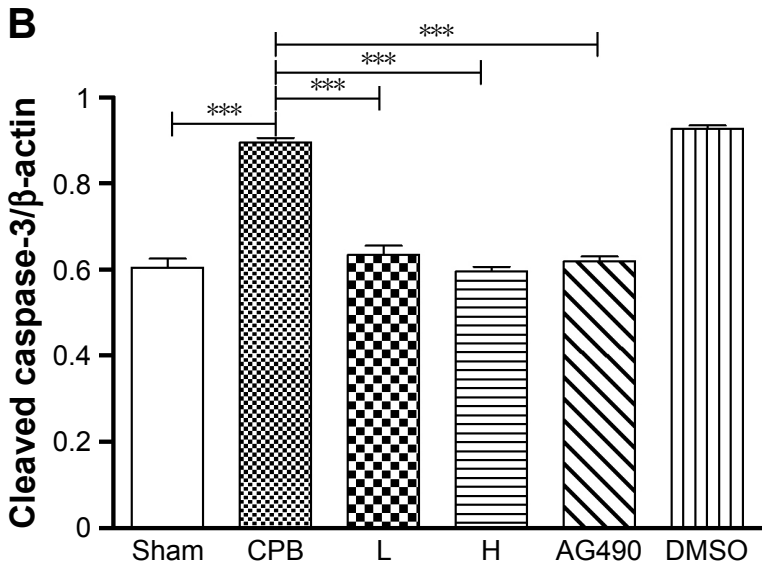

Figure 7 Cleaved caspase-3 protein in the hippocampus.

Notes: (A) Representative Western blot analysis of cleaved caspase 3; (B) cleaved caspase-3 protein. AG490 administered at 10 mg/kg intraperitoneally, DMSO at $0.6796 \mathrm{~mL} / \mathrm{kg}$ intraperitoneally. $* * * P<0.001$.

Abbreviations: DMSO, dimethyl sulfoxide; CPB, cardiopulmonary bypass; L, low dose (dexmedetomidine $2.5 \mu \mathrm{gg} / \mathrm{kg} / \mathrm{h}$ ); H, high dose (dexmedetomidine $5 \mu \mathrm{gg} / \mathrm{kg} / \mathrm{h}$ ).

that dexmedetomidine resulted in a significant decrease in S100 $\beta$ and NSE plasma levels at $t_{1}$ and $t_{2}$ and reduced neuronal apoptosis following $\mathrm{CPB}$ in a dose-dependent manner. Furthermore, we found that the beneficial effects of dexmedetomidine treatment were associated with reduced plasma and cortex levels of the inflammatory cytokine IL6. In addition, dexmedetomidine treatment resulted in a decrease in pJAK2 and pSTAT3 protein levels in the hippocampi of rats that underwent CPB for 2 hours. These effects of dexmedetomidine were similar to those of AG490.

According to clinical data from several medical institutions, the average duration of $\mathrm{CPB}$, included valve, valve and coronary artery-bypass graft, coronary artery-bypass graft, and others (aortic root, ascending aneurysm), is close to 120 minutes. ${ }^{21,22}$ Extracorporeal circulation flow time that was employed in this study was 2 hours. Previous reports have shown that dexmedetomidine exhibits neuroprotective, myocardial-protective and renal-protective functions in animal experiments, clinical anesthesia, and intensive care units. ${ }^{23-26}$ The mechanisms that underpin these phenomena may be related to reductions in inflammation and oxidative stress markers. ${ }^{9}$ A previous report observed that treatment with $5 \mu \mathrm{g} / \mathrm{kg} / \mathrm{h}$ dexmedetomidine can alleviate cerebral damage in diabetic rats, ${ }^{9}$ while treatment with 10 or $20 \mu \mathrm{g} / \mathrm{kg} / \mathrm{h}$ dexmedetomidine has also been shown to reduce renal dysfunction. ${ }^{27}$ According to dose-conversion coefficients following different animal conversions, ${ }^{28}$ rat dosages of $2.5 \mu \mathrm{g} / \mathrm{kg} / \mathrm{h}$ and $5 \mu \mathrm{g} / \mathrm{kg} / \mathrm{h}$ dexmedetomidine are near clinical dosages of $0.3 \mu \mathrm{g} / \mathrm{kg} / \mathrm{h}$ and $0.7 \mu \mathrm{g} / \mathrm{kg} / \mathrm{h}$, respectively, both which are commonly used in clinical procedures. ${ }^{29}$ However, single doses of $1-160 \mu \mathrm{g} / \mathrm{kg}$ have been employed for a variety of brain injuries in several animal experiments. ${ }^{30-32}$ We prefer continuous infusion with a micropump.
A

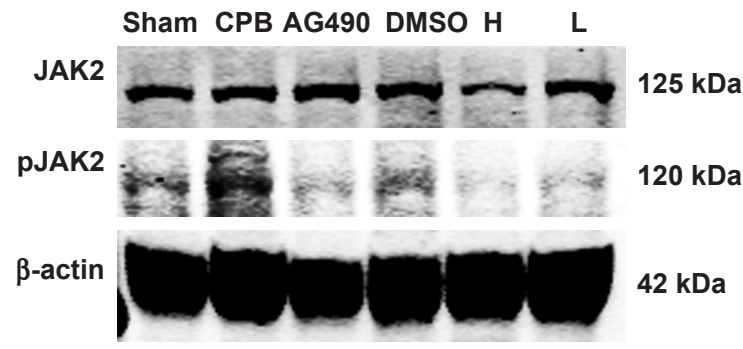

B

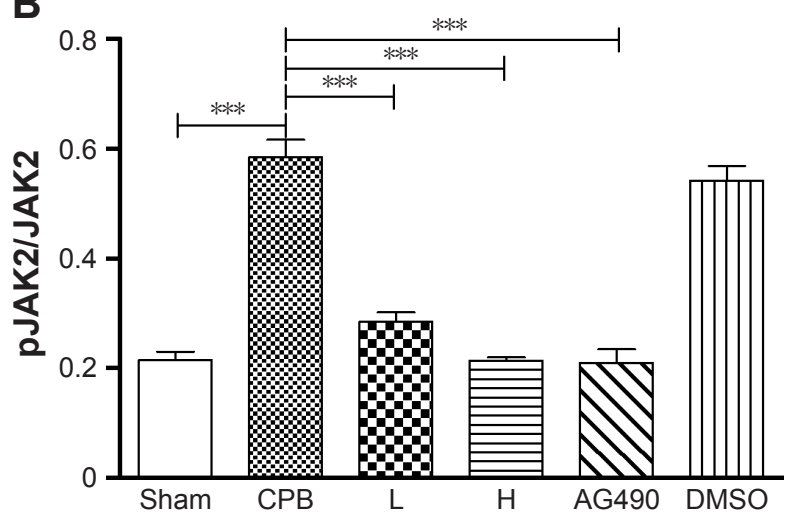

Figure 8 JAK2 and PJAK2 protein levels in the hippocampus.

Notes: (A) Representative Western blot analysis of JAK2 and pJAK2; (B) JAK2 and pJAK2 protein. AG490 administered at $10 \mathrm{mg} / \mathrm{kg}$ intraperitoneally, DMSO at $0.6796 \mathrm{~mL} / \mathrm{kg}$ intraperitoneally. $* * * P<0.001$.

Abbreviations: DMSO, dimethyl sulfoxide; CPB, cardiopulmonary bypass; L, low dose (dexmedetomidine $2.5 \mu \mathrm{g} / \mathrm{kg} / \mathrm{h})$; $\mathrm{H}$, high dose (dexmedetomidine $5 \mu \mathrm{g} / \mathrm{kg} / \mathrm{h}$ ). 
A

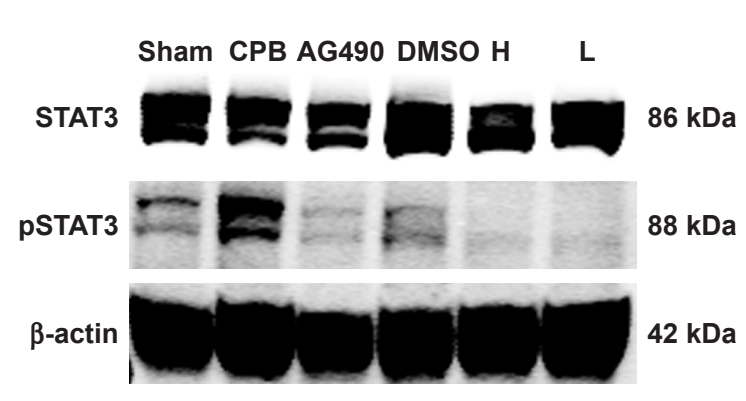

B

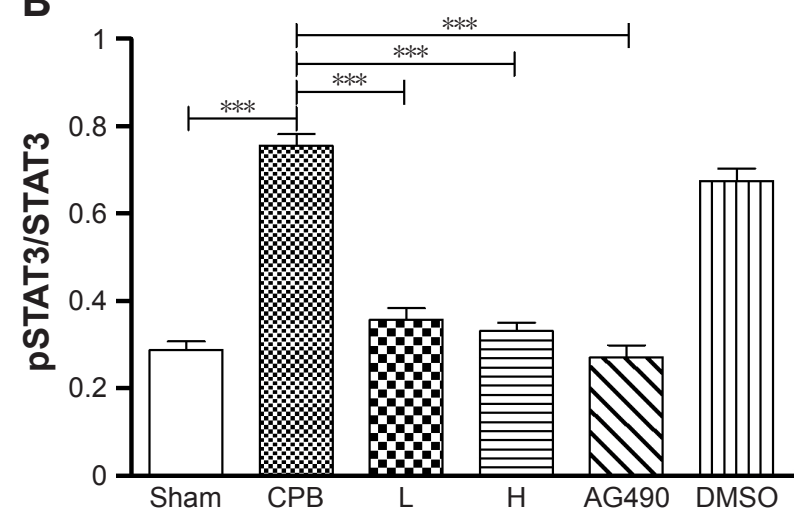

Figure 9 STAT3 and PSTAT3 protein levels in the hippocampus.

Notes: (A) Representative Western blot analysis of STAT3 and PSTAT3 in the hippocampus; (B) STAT3 and pSTAT3 protein. AG490 administered at $10 \mathrm{mg} / \mathrm{kg}$ intraperitoneally, DMSO at $0.6796 \mathrm{~mL} / \mathrm{kg}$ intraperitoneally. ${ }^{*} * * P<0.001$.

Abbreviations: DMSO, dimethyl sulfoxide; CPB, cardiopulmonary bypass; L, low dose (dexmedetomidine $2.5 \mu \mathrm{g} / \mathrm{kg} / \mathrm{h}$ ); H, high dose (dexmedetomidine $5 \mu \mathrm{g} / \mathrm{kg} / \mathrm{h}$ ).

A

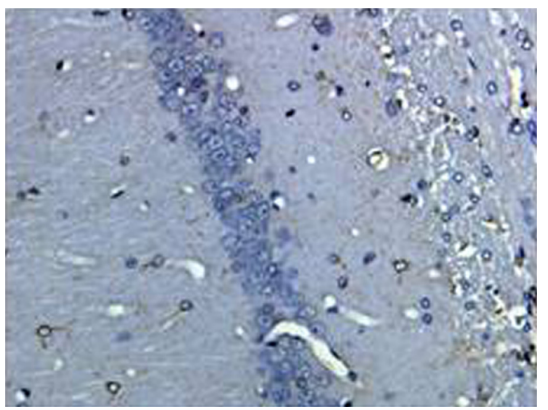

H

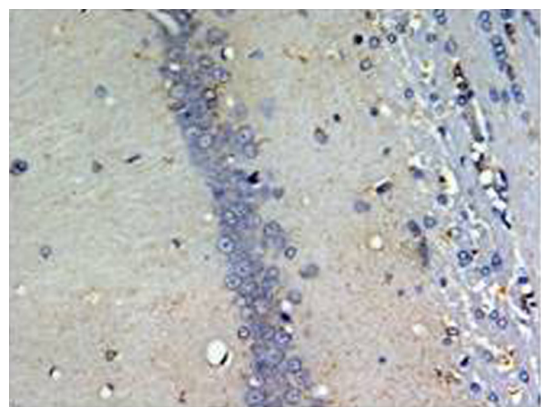

CPB

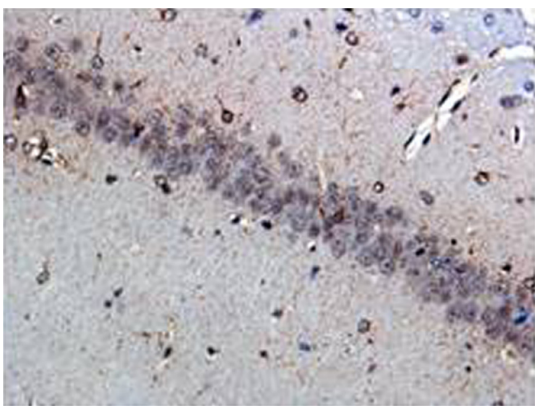

AG490

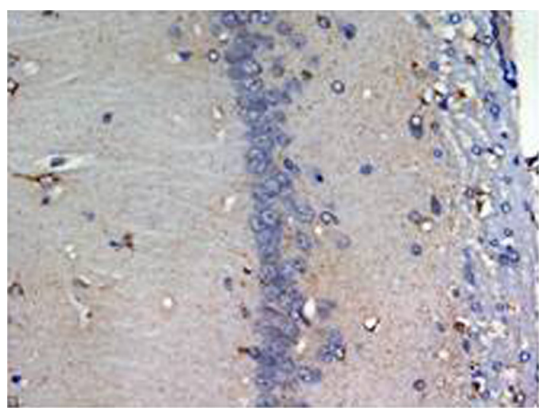

$\mathbf{L}$

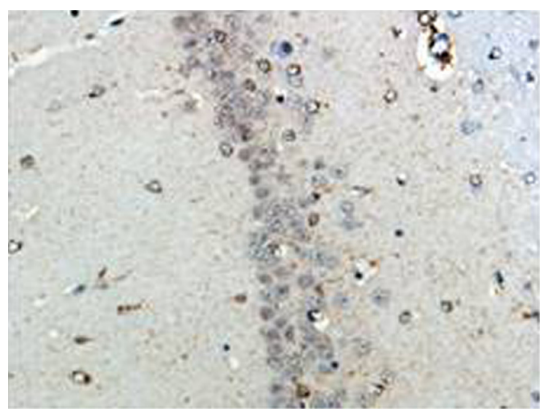

DMSO

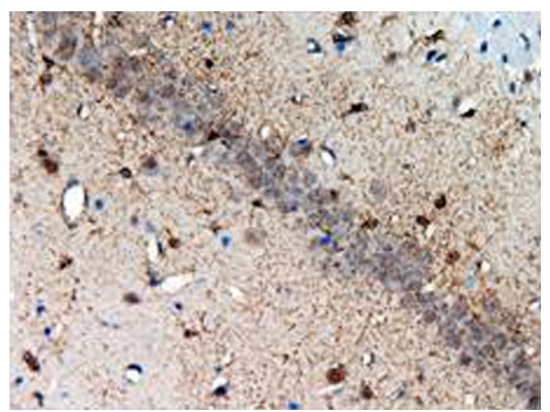

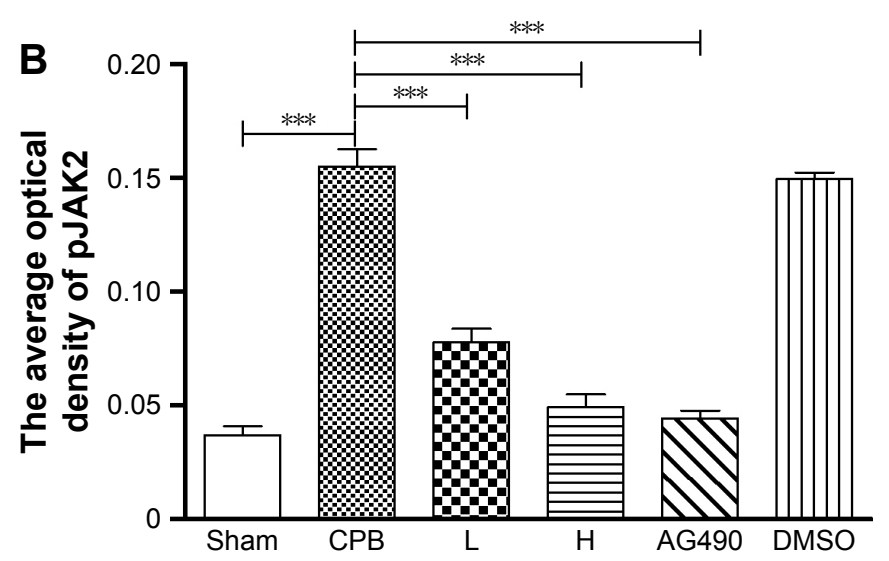

Figure 10 Expression of PJAK2 in hippocampal CAI region by immunohistochemistry.

Notes: (A) Representative images of PJAK2 (400x); (B) PJAK2 expression. AG490 administered at $10 \mathrm{mg} / \mathrm{kg}$ intraperitoneally, DMSO at $0.6796 \mathrm{~mL} / \mathrm{kg}$ intraperitoneally. ****P $<0.001$. Abbreviations: DMSO, dimethyl sulfoxide; CPB, cardiopulmonary bypass; L, low dose (dexmedetomidine $2.5 \mu \mathrm{g} / \mathrm{kg} / \mathrm{h}$ ); $\mathrm{H}$, high dose (dexmedetomidine $5 \mu \mathrm{g} / \mathrm{kg} / \mathrm{h}$ ). 

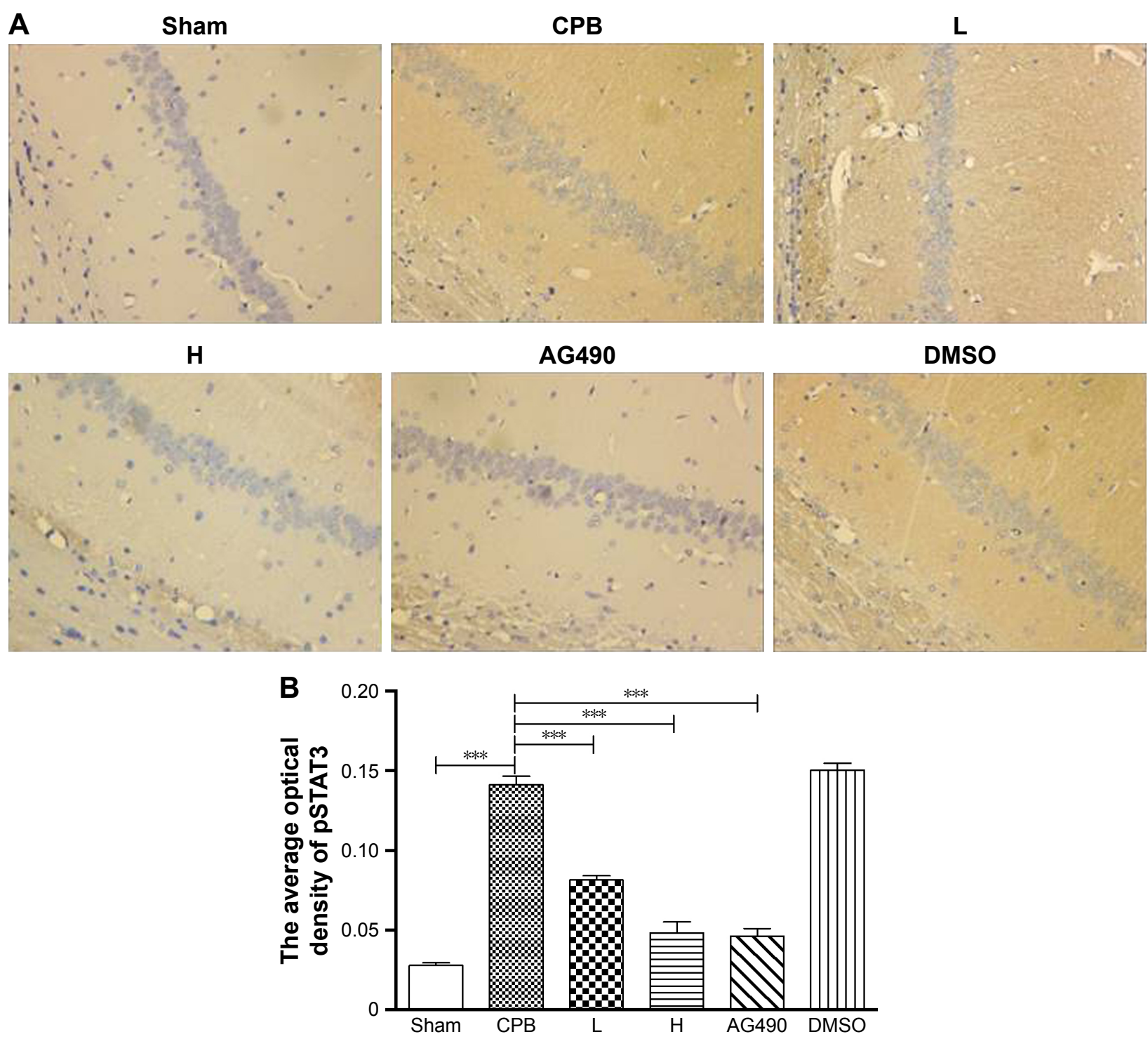

Figure I I Expression of PSTAT3 in hippocampal CAI region by immunohistochemistry.

Notes: (A) Representative images of pSTAT3 (400x); (B) PSTAT3 expression. AG490 administered at $10 \mathrm{mg} / \mathrm{kg}$ intraperitoneally, DMSO at $0.6796 \mathrm{~mL} / \mathrm{kg}$ intraperitoneally. $* * * P<0.001$.

Abbreviations: DMSO, dimethyl sulfoxide; CPB, cardiopulmonary bypass; L, low dose (dexmedetomidine $2.5 \mu \mathrm{g} / \mathrm{kg} / \mathrm{h}$ ); $\mathrm{H}$, high dose (dexmedetomidine $5 \mu \mathrm{gg} / \mathrm{kg} / \mathrm{h}$ ).

S100 $\beta$ and NSE are specific and sensitive biochemical markers for central nervous system damage. Elevations in these markers can be reflective of brain injury. ${ }^{33}$ In this study, S100 $\beta$ and NSE plasma levels were increased after 2 hours of $\mathrm{CPB}$, while dexmedetomidine reduced plasma levels of S100 $\beta$ and NSE. At the same time, dexmedetomidine $5 \mu \mathrm{g} / \mathrm{kg} / \mathrm{h}$ significantly decreased plasma levels of S100 $\beta$ and NSE compared with dexmedetomidine $2.5 \mu \mathrm{g} /$ $\mathrm{kg} / \mathrm{h}$. These results revealed that dexmedetomidine attenuated brain injury related to CPB in a dose-dependent manner. Several reports have suggested that an increase in the level of cleaved caspase 3 results in extensive apoptosis. ${ }^{34,35}$ In this study, increased cleaved caspase-3 levels were observed in group CPB, while dexmedetomidine administration resulted in a decrease in cleaved caspase 3 . These results are in agreement with the observation that dexmedetomidine reduces brain water content and apoptosis of neurons following CPB. Therefore, dexmedetomidine administration confers protection against brain injury induced by CPB.

Systemic inflammatory responses can be induced by CPB. This results in a concomitant increase in inflammatory cytokines, a phenomenon that can result in injury to various organs of the body. ${ }^{5,36,37}$ Several researchers have reported that IL6 and IL10 levels are increased after CPB, and the associated increase in cytokines activates the inflammatory response. ${ }^{36,38}$ 
Our results were in accordance with previous studies. In this study, dexmedetomidine administration resulted in a reduction in IL6 levels in plasma and cortex, while also inhibiting systemic inflammatory reactions that are normally associated with CPB. These results were also in accordance with a previous study that reported that dexmedetomidine reduced the inflammatory response to coronary artery-bypass graft surgery under mini-CPB. ${ }^{39}$

The protein that encodes for IL6 is a major proinflammatory cytokine involved in the inflammatory response associated with CPB ${ }^{40}$ An increase in IL6 levels can activate intracellular signaling. ${ }^{41}$ de Jong et al demonstrated that STAT3 signaling plays a crucial role in the course of systemic inflammation caused by CPB ${ }^{42}$ The JAK-STAT pathway is an important intracellular signal-transduction pathway that relays extracellular signals to nuclei. Activated STAT3 (pSTAT3) is involved in the transcription of genes that mediate inflammation, apoptosis, endothelial cell differentiation, and angiogenesis. ${ }^{43}$

Previous studies have reported that activation of the JAK-STAT signaling pathway may play an important role in organ protection and cell survival during ischemiareperfusion injury. ${ }^{20,44} \mathrm{Kim}$ et $\mathrm{al}^{45}$ demonstrated that sevoflurane postconditioning can reduce neuronal apoptosis by increasing pJAK2 and pSTAT3 expression after transient global ischemia in rats. Zhao et a ${ }^{15}$ showed that activation of the JAK2-STAT pathway may be involved in neurological function recovery after traumatic brain injury.

However, some studies have shown that inhibition of activation of the JAK2-STAT3 pathway has organ protection. Hristova et $\mathrm{al}^{46}$ demonstrated that inhibition of STAT3 phosphorylation can reduce neonatal hypoxic-ischemic brain injury. Si et a ${ }^{11}$ showed that administration of dexmedetomidine protects against renal ischemia and reperfusion injury by inhibiting JAK-STAT signaling activation. Jia et al ${ }^{47}$ demonstrated that propofol postconditioning attenuates hippocampus ischemia-reperfusion injury by reducing the expression of JAK2 and STAT3 in rats after autogenous orthotropic liver transplantation.

These different results may be related to the experimental model, experimental object, experimental conditions, and degree of injury. We hypothesize that when the body is injured, the body can play a protective role by activating the JAK2-STAT3 pathway. However, if the JAK2-STAT3 pathway is activated excessively after the body is injured, the use of drugs and other methods to protect the body can appear as inhibition of activation of the JAK2-STAT3 pathway, such that it can play an organ-protective effect.
In this study, we observed that dexmedetomidine caused a decrease in pJAK2 and pSTAT3 protein levels in the hippocampi of rats that underwent CPB. AG490, an inhibitor of JAK2, was used to verify that dexmedetomidine exerted its neuroprotective effect via inhibiting JAK2-STAT3 signaling. All dexmedetomidine effects were similar to those in group AG490. These results suggest that dexmedetomidine plays a role in reducing the expression of pJAK2 and pSTAT3 in the protective effect of brain injury following CPB. These findings further validate the importance of the JAK-STAT signaling pathway in injury amelioration induced by dexmedetomidine.

\section{Conclusion}

In conclusion, dexmedetomidine can reduce inflammatory reactions and neuronal apoptosis related to CPB. The JAK2-STAT3 pathway plays an important role in the neuroprotective effects of dexmedetomidine. Dexmedetomidine provides neuroprotection during $\mathrm{CPB}$ in a dosedependent manner.

\section{Acknowledgments}

This work was supported by the Natural Science Foundation of China (81373498), Science Study and Technology Development Program of Guangxi (1355005-4-2), Natural Science Foundation of Guangxi (2015GXNSFBA139139), Youth Science Foundation of Guangxi Medical University (GXMUYSF2014041) and the Department of Education Scientific Research Subject of Guangxi (KY2016YB079), China.

\section{Author contributions}

YHC and YBX conceived and designed the experiments, YHC, XZ, and LFZ performed the experiments, YHC, XZ, BDZ, and GDH analyzed the data, YHC and GDH wrote the paper, YBX and YHC were in charge of administration, and $\mathrm{BDZ}$ and $\mathrm{YBX}$ were in charge of project supervision. All authors contributed toward data analysis, drafting and revising the paper and agree to be accountable for all aspects of the work.

\section{Disclosure}

The authors report no conflicts of interest in this work.

\section{References}

1. Caputo M, Mokhtari A, Miceli A, et al. Controlled reoxygenation during cardiopulmonary bypass decreases markers of organ damage, inflammation, and oxidative stress in single-ventricle patients undergoing pediatric heart surgery. J Thorac Cardiovasc Surg. 2014;148(3): 792-801.e8 
2. Homi HM, Jones WL, de Lange F, Mackensen GB, Grocott HP. Exacerbation of systemic inflammation and increased cerebral infarct volume with cardiopulmonary bypass after focal cerebral ischemia in the rat. J Thorac Cardiovasc Surg. 2010;140(3):660-666.e1.

3. McDonagh DL, Berger M, Mathew JP, Graffagnino C, Milano CA, Newman MF. Neurological complications of cardiac surgery. Lancet Neurol. 2014;13(5):490-502.

4. Patel N, Minhas JS, Chung EM. Risk factors associated with cognitive decline after cardiac surgery: a systematic review. Cardiovasc Psychiatry Neurol. 2015;2015:370612.

5. Howell KW, Cleveland JC Jr, Meng X, et al. Interleukin 6 production during cardiac surgery correlates with increasing age. J Surg Res. 2016; 201(1):76-81

6. Ouk T, Amr G, Azzaoui R, et al. Lipid-lowering drugs prevent neurovascular and cognitive consequences of cardiopulmonary bypass. Vascul Pharmacol. 2016;80:59-66.

7. Zhang W, Weng G, Li M, et al. Original Research: Establishment of an early embolus-related cerebral injury model after cardiopulmonary bypass in miniature pigs. Exp Biol Med (Maywood). 2016;241(16): $1819-1824$

8. Liao Z, Cao D, Han X, et al. Both JNK and P38 MAPK pathways participate in the protection by dexmedetomidine against isofluraneinduced neuroapoptosis in the hippocampus of neonatal rats. Brain Res Bull. 2014;107:69-78.

9. Zeng X, Wang H, Xing X, Wang Q, Li W. Dexmedetomidine protects against transient global cerebral ischemia/reperfusion induced oxidative stress and inflammation in diabetic rats. PLoS One. 2016;11(3): $\mathrm{e} 0151620$

10. Si YN, Bao HG, Xu L, et al. Dexmedetomidine protects against ischemia/reperfusion injury in rat kidney. Eur Rev Med Pharmacol Sci. 2014;18(13):1843-1851.

11. Si Y, Bao H, Han L, et al. Dexmedetomidine protects against renal ischemia and reperfusion injury by inhibiting the JAK/STAT signaling activation. $J$ Transl Med. 2013;11:141.

12. Zhao J, Li G, Zhang Y, Su X, Hang C. The potential role of JAK2/ STAT3 pathway on the anti-apoptotic effect of recombinant human erythropoietin (rhEPO) after experimental traumatic brain injury of rats. Cytokine. 2011;56(2):343-350.

13. Tao Z, Cheng M, Wang SC, et al. JAK2/STAT3 pathway mediating inflammatory responses in heatstroke-induced rats. Int J Clin Exp Pathol. 2015;8(6):6732-6739.

14. Oliva AA Jr, Kang Y, Sanchez-Molano J, Furones C, Atkins CM. STAT3 signaling after traumatic brain injury. $J$ Neurochem. 2012;120(5): 710-720.

15. Zhao JB, Zhang Y, Li GZ, Su XF, Hang CH. Activation of JAK2/STAT pathway in cerebral cortex after experimental traumatic brain injury of rats. Neurosci Lett. 2011;498(2):147-152.

16. Kim J, Yin T, Yin M, et al. Examination of physiological function and biochemical disorders in a rat model of prolonged asphyxia-induced cardiac arrest followed by cardio pulmonary bypass resuscitation. PLoS One. 2014;9(11):e112012.

17. Lv J, Wei Y, Chen Y, et al. Dexmedetomidine attenuates propofolinduce neuroapoptosis partly via the activation of the PI3k/Akt/ GSK $3 \beta$ pathway in the hippocampus of neonatal rats. Environ Toxicol Pharmacol. 2017;52:121-128.

18. Hatashita S, Hoff JT, Salamat SM. Ischemic brain edema and the osmotic gradient between blood and brain. JCereb Blood Flow Metab. 1988;8(4):552-559.

19. Komine-Kobayashi M, Zhang N, Liu M, et al. Neuroprotective effect of recombinant human granulocyte colony-stimulating factor in transient focal ischemia of mice. J Cereb Blood Flow Metab. 2006;26(3):402-413.

20. Liu X, Zhang X, Zhang J, et al. Diosmin protects against cerebral ischemia/reperfusion injury through activating JAK2/STAT3 signal pathway in mice. Neuroscience. 2014;268:318-327.

21. Hori D, Hogue CW Jr, Shah A, et al. Cerebral autoregulation monitoring with ultrasound-tagged near-infrared spectroscopy in cardiac surgery patients. Anesth Analg. 2015;121(5):1187-1193.
22. Matata BM, Scawn N, Morgan M, et al. A single-center randomized trial of intraoperative zero-balanced ultrafiltration during cardiopulmonary bypass for patients with impaired kidney function undergoing cardiac surgery. J Cardiothorac Vasc Anesth. 2015;29(5): $1236-1247$

23. Zhang XK, Zhou XP, Zhang Q, Zhu F. The preventive effects of dexmedetomidine against intestinal ischemia-reperfusion injury in Wistar rats. Iran J Basic Med Sci. 2015;18(6):604-609.

24. Wang Y, Wu C, Han B, et al. Dexmedetomidine attenuates repeated propofol exposure-induced hippocampal apoptosis, PI3K/Akt/Gsk-3 $\beta$ signaling disruption, and juvenile cognitive deficits in neonatal rats. Mol Med Rep. 2016;14(1):769-775.

25. Hwang L, Choi IY, Kim SE, et al. Dexmedetomidine ameliorates intracerebral hemorrhage-induced memory impairment by inhibiting apoptosis and enhancing brain-derived neurotrophic factor expression in the rat hippocampus. Int J Mol Med. 2013;31(5):1047-1056.

26. Cheng XY, Gu XY, Gao Q, Zong QF, Li XH, Zhang Y. Effects of dexmedetomidine postconditioning on myocardial ischemia and the role of the PI3K/Akt-dependent signaling pathway in reperfusion injury. Mol Med Rep. 2016;14(1):797-803.

27. Sugita S, Okabe T, Sakamoto A. Continuous infusion of dexmedetomidine improves renal ischemia-reperfusion injury in rat kidney. J Nippon Med Sch. 2013;80(2):131-139.

28. Reagan-Shaw S, Nihal M, Ahmad N. Dose translation from animal to human studies revisited. FASEB J. 2008;22(3):659-661.

29. Kunisawa T, Ueno M, Kurosawa A, et al. Dexmedetomidine can stabilize hemodynamics and spare anesthetics before cardiopulmonary bypass. J Anesth. 2011;25(6):818-822.

30. Zhu YJ, Peng K, Meng XW, Ji FH. Attenuation of neuroinflammation by dexmedetomidine is associated with activation of a cholinergic antiinflammatory pathway in a rat tibial fracture model. Brain Res. 2016; 1644:1-8.

31. Sifringer M, von Haefen C, Krain M, et al. Neuroprotective effect of dexmedetomidine on hyperoxia-induced toxicity in the neonatal rat brain. Oxid Med Cell Longev. 2015;2015:530371.

32. Pan W, Lin L, Zhang N, et al. Neuroprotective effects of dexmedetomidine against hypoxia-induced nervous system injury are related to inhibition of NF-кB/COX-2 pathways. Cell Mol Neurobiol. 2016; 36(7):1179-1188.

33. Luo X, Zheng X, Huang H. Protective effects of dexmedetomidine on brain function of glioma patients undergoing craniotomy resection and its underlying mechanism. Clin Neurol Neurosurg. 2016;146: $105-108$.

34. Deng H, Zuo X, Zhang J, et al. $\alpha$-Lipoic acid protects against cerebral ischemia/reperfusion-induced injury in rats. Mol Med Rep. 2015;11(5): 3659-3665.

35. Kim YR, Kim HN, Jang JY, et al. Effects of electroacupuncture on apoptotic pathways in a rat model of focal cerebral ischemia. Int J Mol Med. 2013;32(6):1303-1310.

36. Fujii Y, Shirai M, Inamori S, et al. Insufflation of hydrogen gas restrains the inflammatory response of cardiopulmonary bypass in a rat model. Artif Organs. 2013;37(2):136-141.

37. Trop S, Marshall JC, Mazer CD, et al. Perioperative cardiovascular system failure in South Asians undergoing cardiopulmonary bypass is associated with prolonged inflammation and increased Toll-like receptor signaling in inflammatory monocytes. J Surg Res. 2014; 187(1):43-52.

38. Jongman RM, Zijlstra JG, Kok WF, et al. Off-pump CABG surgery reduces systemic inflammation compared with on-pump surgery but does not change systemic endothelial responses: a prospective randomized study. Shock. 2014;42(2):121-128.

39. Bulow NM, Colpo E, Pereira RP, et al. Dexmedetomidine decreases the inflammatory response to myocardial surgery under mini-cardiopulmonary bypass. Braz J Med Biol Res. 2016;49(4):e4646.

40. Podgoreanu MV, White WD, Morris RW, et al. Inflammatory gene polymorphisms and risk of postoperative myocardial infarction after cardiac surgery. Circulation. 2006;114(1 Suppl):I275-I281. 
41. Steinbrenner H, Bilgic E, Pinto A, et al. Selenium pretreatment for mitigation of ischemia/reperfusion injury in cardiovascular surgery: influence on acute organ damage and inflammatory response. Inflammation. 2016;39(4):1363-1376.

42. de Jong PR, Schadenberg AW, van den Broek T, et al. STAT3 regulates monocyte TNF-alpha production in systemic inflammation caused by cardiac surgery with cardiopulmonary bypass. PLoS One. 2012; 7(4):e35070.

43. Owais K, Huang T, Mahmood F, et al. Cardiopulmonary bypass decreases activation of the signal transducer and activator of transcription 3 (STAT3) pathway in diabetic human myocardium. Ann Thorac Surg. 2015;100(5):1636-1645.

44. Li L, Li H, Li M. Curcumin protects against cerebral ischemia-reperfusion injury by activating JAK2/STAT3 signaling pathway in rats. Int J Clin Exp Med. 2015;8(9):14985-14991.
45. Kim HC, Kim E, Bae JI, et al. Sevoflurane postconditioning reduces apoptosis by activating the JAK-STAT pathway after transient global cerebral ischemia in rats. J Neurosurg Anesthesiol. 2017;29(1):37-45.

46. Hristova M, Rocha-Ferreira E, Fontana X, et al. Inhibition of signal transducer and activator of transcription 3 (STAT3) reduces neonatal hypoxicischaemic brain damage. J Neurochem. 2016;136(5):981-994.

47. Jia L, Wang F, Gu X, et al. Propofol postconditioning attenuates hippocampus ischemia-reperfusion injury via modulating JAK2/STAT3 pathway in rats after autogenous orthotropic liver transplantation. Brain Res. 2017;1657:202-207.

\section{Publish your work in this journal}

Drug Design, Development and Therapy is an international, peerreviewed open-access journal that spans the spectrum of drug design and development through to clinical applications. Clinical outcomes, patient safety, and programs for the development and effective, safe, and sustained use of medicines are the features of the journal, which has also been accepted for indexing on PubMed Central. The manuscript management system is completely online and includes a very quick and fair peer-review system, which is all easy to use. Visit http://www.dovepress.com/testimonials.php to read real quotes from published authors.

Submit your manuscript here: http://www.dovepress.com/drug-design-development-and-therapy-journal 